ORIGINAL ARTICLE

\title{
Evaluating Soft Tissue Thickness in Different Anterior-Posterior Skeletal Classifications Informative
}

\author{
SABA SAFARZADEH ${ }^{1}$, MOHAMMAD MONIRIFARD ${ }^{2}$, FARINAZ SHIRBAN ${ }^{3 *}$ \\ ${ }^{1}$ Post Graduate Student, Dental Students' Research Committee, Department of Orthodontics, School of Dentistry, Isfahan University of \\ Medical Sciences, Isfahan, Iran. \\ ${ }^{2}$ Department of Orthodontics, Dental Materials Research Center, Dental Research Institute, School of Dentistry, Isfahan University of \\ Medical Sciences, Isfahan, Iran. \\ ${ }^{3}$ Department of Orthodontics, Dental Research Center, Dental Research Institute, School of Dentistry, Isfahan University of Medical \\ Sciences, Isfahan, Iran. \\ Saba Safarzadeh Orcid number: https://orcid.org/0000-0003-1540-8669 E-mail: SabaSafarzade@yahoo.com \\ Mohammad Monirifard, Orcid number: https://orcid.org/0000-0001-7798-9935 E-mail: mmonirifard@yahoo.com \\ Farinaz Shirban* (corresponding author), Orcid number: https://orcid.org/0000-0003-4869-7794 E-mail: shirban123@yahoo.com \\ Cell: (+98 913) 3657389
}

\begin{abstract}
Background: The soft tissue thickness is affected by anterior posterior skeletal relationship. This study has been designed to evaluate the soft tissue thickness among different anterior posterior skeletal classifications.

Material and Methods: In this cross-sectional study, 206 digital lateral cephalometric radiographs from patients undergoing treatment at several orthodontic clinics were evaluated. The skeletal group was determined by the ANB angle. The planned points were determined on digital radiographs using the Digimizer.V4.1.1.0 and then the measurements were done. Data were analyzed by Kruskal-Wallis, Mann-Whitney, Pearson Correlation and Spearman tests.

Results: Significant difference showed between soft tissue thickness at Subnasale between class I and II, at Subnasale, Labrale Superius, Stomion Superius, Stomion Inferius between class I and III and at Subnasale, Labrale Superius, Stomion Superius, Stomion Inferius, between class II and III. Among the women, soft tissue thickness at subnasale were higher in class I group compared to class II, Subnasale, Labrale Superius, Stomion Superius, Stomion Inferius were higher in class III compared to class I and at Labrale Inferius was higher in class II compared to class III. Among the men, soft tissue thickness at Stomion Superius, Stomion Inferius and Labrale Superius were higher in class III group compared to class I and II.

Conclusion: We established that soft tissue thickness in some landmarks were significantly different between skeletal groups and gender. There is a correlation in soft tissue thickness and skeletal relationship at Stomion Inferius, Subnasale, Labrale Superius, Stomion Superius.

Keywords: Soft Tissue, Skeletal Classification, Cephalometry
\end{abstract}

\section{INTRODUCTION}

Soft tissue evaluation is essential in the diagnosis and treatment planning of patients under orthodontic treatments or maxillofacial orthognathic surgeries. Hence, knowledge regarding the normal conditions of soft and hard tissues is necessary for establishing facial aesthetics and creating functional occlusion. ${ }^{1}$

Soft tissue thickness has received much more attention since the advent of soft tissue paradigm in orthodontics. $^{2}$ In addition, soft tissue has recently been proposed to be used in facial restorations to identify individuals based on the skull remnants in forensics. ${ }^{3}$

New techniques of facial modelling such as twodimensional, manual three-dimensional and computer three-dimensional methods that reconstruct facial muscles and structure according to the depth of soft tissue at specific points of the skull have been proposed. These techniques are frequently used in corrective facial surgeries. ${ }^{4,5}$ Thus, determining the thickness of soft tissue at various parts of the face is highly important.

There are five methods for measuring soft tissue thickness as follows: 1 . Needle puncture: measurement by the insertion of graded needles in the tissue of the corpse, ${ }^{6}$ 2. Ultrasonography, ${ }^{7}$ 3. X-ray (lateral cephalogram is a standardized, reproducible and routine radiograph for diagnosis and treatment planning in orthodontics ${ }^{8}$ as was used in this study), 4. Magnetic resonance imaging (MRI), ${ }^{9}$ and 5 . Computed tomography (CT). ${ }^{9}$ These methods have advantages and disadvantages of their own, and none can be considered as the most superior technique. Studies have shown that soft tissue thickness is influenced by the following parameters:

- $\quad$ Age (adult or child) and gender: soft tissue thickness is higher in men than in women on average. ${ }^{10,11}$

- $\quad$ Race: for each population, the indices appropriate for that population should be used. ${ }^{12}$

- Vertical growth pattern: soft tissue is thinner in longfaced people ${ }^{13}$.

- Anterior-posterior skeletal classifications: in orthodontics, people are classified into three skeletal classes based on the anatomical relationship between maxilla and mandible ${ }^{14}$ and Various studies have reported differences in soft tissue thickness in similar races among these three classes. ${ }^{15,16}$

Edward Angle classified dental malocclusion into four classes, namely normal malocclusion, class I malocclusion, class II malocclusion and class III malocclusion. ${ }^{17}$ This classification can also be used for patients' skeletal conditions based on the anterior-posterior position of the maxilla and mandible relative to one another.

In a study of a Brazilian population, no significant difference was found in soft tissue thickness among 
patients with anterior-posterior skeletal problems, but there were differences at the upper lip, stomion and pogonion points among those with class II and III malocclusion. ${ }^{18}$ In another study among a Japanese population, different soft tissue thicknesses were observed among various skeletal classes in the two genders at subnasal, stomion and upper lip areas, and these differences were found to be more in women than in men. ${ }^{19}$ Further, a study of a local Turkish population showed differences among various skeletal classes at the upper and lower lips and stomion point, and the mean soft tissue thickness was higher in men than in women. ${ }^{20}$ Moreover, a research conducted in Pakistan confirmed that the mean soft tissue thickness was higher among men than women, and this difference was found to be more in skeletal classes II and III than in class I. ${ }^{21}$ Furthermore, a study carried out on an Anatolian population demonstrated differences between skeletal classes in both genders, and these differences were more dependent on gender than on skeletal class. ${ }^{22}$

As stated, generalizing information of populations with different races is not strategic in treatment contexts. Also, there is a shortage of data concerning the Iranian population in this regard. Thus, the present study was aimed at evaluating soft tissue thickness in different anterior-posterior skeletal classifications.

\section{MATERIAL AND METHODS}

This descriptive cross-sectional study was preformed using 206 lateral cephalometric radiographs of patients under treatment in several orthodontic clinics in Isfahan, Iran. The frequency of data is presented in Table 1.

Sample preparation: The inclusion criteria were as follows: 1) patients' lateral cephalometric radiographs with class II and III skeletal classification based on cephalometric parameters and skeletal class I with dental problems who had lateral cephalometry in their clinic files; 2) no evidence of previous orthodontic treatment or surgery, 3) high-quality cephalometric radiographs for landmark identification, 4) no skeletal asymmetry, and 5) age range of $18-30$ years $^{22}$ or vertebral maturation after stage $\mathrm{CS}_{6}$ when lateral cephalometry was taken.

The samples with the following characteristics were excluded from the study: 1) presence of abnormal vertical facial relations (normal range: mandible plane angle (MPA) of $\left.21-28^{\circ}\right)^{23}$ and 2) lips not being at rest in lateral cephalometric radiographs.

Skeletal classification was performed by ANB angle, ${ }^{15}$, 22, 24 which indicates the relations between maxilla and mandible. Another anterior-posterior index measured in this study was A-B plane to facial plane angle. As for ANB angle, the following numerical figures were considered: 23

Class I, ANB angle $=0-4^{\circ}$

Class II, ANB angle $>4^{\circ}$

Class III, ANB angle $<0^{\circ}$.

After classification of lateral cephalometric radiographs, the study points were determined by an orthodontist on digital radiographs using Digitizer. V4.1.1.0 (a free software produced by MedCale Software, Belgium and the U.S.) (http://www.digimizer.com/manual/alicenseagreement.php), a software for the analysis of digital images. ${ }^{25}$ Then, the distances were measured by a trained dental student according to what follows. Further, to prevent observer bias, all cephalograms were encoded; therefore, the observer was blinded to the patients' information during the measurements (Figure 1).

To assess intra-observer error, cephalometric X-ray films from 30 subjects were selected randomly, and the measurements repeated were by a single practitioner at 3week intervals. Intraclass correlation coefficient was greater than 0.9 for all the measurements. The points, distances and measurement method are demonstrated in Figure 1.

The methods for soft tissue thickness calculation at the given points were as follows:

Points 1, 2, 3 and 9: the shortest distance from the given point on the bone to the soft tissue on it, which was measured on the line parallel to the Frankfort horizontal plane $^{20}$.

Point 4: the distance between point A and subnasal point. Point 5: the distance between prosthion and labrale superius

Point 6: a line parallel to the Frankfort horizontal plane was drawn from stomion point, and then the given distance at the intersection of this line and the labial surface of incisors was measured. When the lips were separated, the distances between the upper and lower stomions and labial surface of the incisors of the same jaw, as mentioned above, were measured.

Point 7: the distance between infradentale and labrale inferius.

Point 8: the distance between point $B$ and the deepest point of the labiomental crease.

Point 10: a line perpendicular to the Frankfort plane was drawn from the given point on the bone and was extended to the opposite side to cross the soft tissue. This distance was then measured.

To take full advantage of image contrast and to improve the quality of observations, all the measurements were carried out in a room with dim light, and contrast and brightness tools in the software were used.

Statistical analysis: Soft tissue thickness values were divided by the size of SN line for allowing image calibration in the cephalometric analysis.

Kolmogorov-Smirnov test was run to determine the normality of the data, indicating the data was not normal. Therefore, non-parametric tests were run. Kruskal-Wallis and Mann-Whitney $U$ tests were used to compare the means between genders and skeletal classes. Spearman and Pearson correlation coefficient tests were employed to analyze the difference in soft tissue thickness and correlation of data between skeletal classes. A $P$-value of less than 0.05 was considered significant.

\section{RESULTS}

The results of Kruskal-Wallis test showed a significant difference between the two genders at stomion, stomion superius, labrale superius and subnasal inferius points $(p<0.001)$. Also, the Mann-Whitney test indicated significant differences in soft tissue thickness between classes I and II at subnasal point $(\mathrm{p}=0.002)$, between classes I and III at subnasal, labrale superius, stomion superius and stomion inferius points $(p<0.001)$ and between classes II and III at subnasal, labrale superius, stomion superius and stomion inferius points $(p<0.001)$. 
The frequency of data and results of Mann-Whitney test for comparison of the mean values of soft tissue thickness divided by the size of SN line between the two genders in each skeletal class are presented in Table 1. Also, the results of Mann-Whitney regarding the comparison between skeletal classes according to gender are shown in Table 2.

The findings of Spearman test showed significant differences between different skeletal classes in terms of soft tissue thickness at subnasal $(p=0.001, r=0.230)$, labrale superius $(p<0.001, r=0.287)$, stomion superius $(p=0.001, r=0.233)$ and stomion inferius $(p=0.001, r=0.235)$ points. As shown, the correlation coefficient $(r)$ rate of data was low; therefore, despite the significant differences, the correlation of numerical values of soft tissue thickness at the aforementioned points of the skeletal classes was not considerable.

The results of Pearson correlation test indicated significant differences in soft tissue thickness between skeletal classes at subnasal $(p<0.001, r=-0.460)$, labrale superius $(p<0.001, r=-0.373)$ and stomion superius $(p<0.001, r=-0.315)$ points, and there was a small negative correlation between numerical values of soft tissue thickness and numerical values of skeletal class determinant (ANB). Moreover, this test indicated a significant difference in soft tissue thickness between skeletal classes at labrale inferius $(p=0.002, r=0.217)$ and labiomental $(p=0.004, r=0.202)$ points, but there was a small positive correlation between the aforementioned indices.

Table 1. Mean values of soft tissue thickness divided by the size of $\mathrm{SN}^{*}$ line and standard deviations between the two genders in each skeletal class

\begin{tabular}{|c|c|c|c|c|c|c|}
\hline & Group & Gender & $\mathrm{N}$ & Mean $\left(^{\star}\right)$ & Standard deviation & $\mathrm{P}$ value \\
\hline \multirow{6}{*}{ Glabella } & \multirow{2}{*}{ Class I } & Female & 43 & 0.0792 & 0.01633 & \multirow{2}{*}{0.911} \\
\hline & & Male & 21 & 0.0819 & 0.01209 & \\
\hline & \multirow{2}{*}{ Class II } & Female & 54 & 0.0754 & 0.01501 & \multirow[b]{2}{*}{0.440} \\
\hline & & Male & 10 & 0.0740 & 0.01174 & \\
\hline & \multirow[b]{2}{*}{ ClassIII } & Female & 42 & 0.0800 & 0.01887 & \multirow[b]{2}{*}{0.107} \\
\hline & & Male & 26 & 0.0831 & 0.01715 & \\
\hline \multirow{6}{*}{ Nasion } & \multirow{2}{*}{ Classl } & Female & 41 & 0.0744 & 0.02169 & \multirow[b]{2}{*}{0.111} \\
\hline & & Male & 21 & 0.0810 & 0.02528 & \\
\hline & \multirow{2}{*}{ ClassII } & Female & 51 & 0.0688 & 0.01740 & \multirow[b]{2}{*}{0.034} \\
\hline & & Male & 10 & 0.0860 & 0.02547 & \\
\hline & \multirow{2}{*}{ ClassIII } & Female & 41 & 0.0734 & 0.02243 & \multirow{2}{*}{0.097} \\
\hline & & Male & 26 & 0.0819 & 0.02433 & \\
\hline \multirow{6}{*}{ Rhinion } & \multirow{2}{*}{ Classl } & Female & 42 & 0.0405 & 0.01011 & \multirow{2}{*}{0.015} \\
\hline & & Male & 21 & 0.0438 & 0.01024 & \\
\hline & \multirow{2}{*}{ Classll } & Female & 54 & 0.0398 & 0.01055 & \multirow{2}{*}{0.046} \\
\hline & & Male & 10 & 0.0510 & 0.00994 & \\
\hline & \multirow{2}{*}{ ClassIII } & Female & 41 & 0.0449 & 0.01468 & \multirow{2}{*}{0.110} \\
\hline & & Male & 26 & 0.0488 & 0.00952 & \\
\hline \multirow{6}{*}{ Subnasale } & \multirow{2}{*}{ Classl } & Female & 42 & 0.2200 & 0.02776 & \multirow{2}{*}{0.001} \\
\hline & & Male & 21 & 0.2676 & 0.02773 & \\
\hline & \multirow{2}{*}{ ClassIl } & Female & 54 & 0.2196 & 0.03102 & \multirow{2}{*}{0.007} \\
\hline & & Male & 10 & 0.2400 & 0.02160 & \\
\hline & \multirow{2}{*}{ ClassIII } & Female & 41 & 0.2434 & 0.03624 & \multirow{2}{*}{0.065} \\
\hline & & Male & 26 & 0.2600 & 0.03429 & \\
\hline \multirow{3}{*}{ Labrale Superius } & \multirow{2}{*}{ Classl } & Female & 43 & 0.1833 & 0.02843 & \multirow[b]{2}{*}{0.001} \\
\hline & & Male & 21 & 0.2167 & 0.03055 & \\
\hline & ClassII & Female & 54 & 0.1865 & 0.02593 & 0.379 \\
\hline
\end{tabular}

Table 2. Comparison of soft tissue thickness values divided by the size of SN line among skeletal classes according to gender

\begin{tabular}{|c|c|c|c|c|c|c|}
\hline \multirow[t]{3}{*}{ the Le Com } & 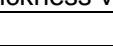 & Male & 10 & 0.2050 & 0.02991 & \multirow[b]{3}{*}{0.001} \\
\hline & \multirow{2}{*}{ ClassIII } & Female & 42 & 0.2055 & 0.03078 & \\
\hline & & Male & 26 & 0.2404 & 0.03268 & \\
\hline \multirow{6}{*}{ Stomion Superius } & \multirow{2}{*}{ Classl } & Female & 43 & 0.0774 & 0.02812 & \multirow{2}{*}{0.015} \\
\hline & & Male & 21 & 0.1038 & 0.03186 & \\
\hline & \multirow{2}{*}{ Classll } & Female & 54 & 0.0756 & 0.02925 & \multirow{2}{*}{0.174} \\
\hline & & Male & 10 & 0.0980 & 0.02251 & \\
\hline & \multirow{2}{*}{ ClassIII } & Female & 42 & 0.0929 & 0.03402 & \multirow{2}{*}{0.002} \\
\hline & & Male & 26 & 0.1169 & 0.04550 & \\
\hline \multirow{6}{*}{ Stomion Inferius } & \multirow{2}{*}{ Classl } & Female & 43 & 0.0774 & 0.02838 & \multirow{2}{*}{0.023} \\
\hline & & Male & 21 & 0.1010 & 0.03223 & \\
\hline & \multirow{2}{*}{ Classll } & Female & 54 & 0.2578 & 1.35110 & \multirow{2}{*}{0.936} \\
\hline & & Male & 10 & 0.0870 & 0.02163 & \\
\hline & \multirow{2}{*}{ ClassIII } & Female & 42 & 0.0905 & 0.03450 & \multirow{2}{*}{0.002} \\
\hline & & Male & 26 & 0.1258 & 0.06469 & \\
\hline \multirow{2}{*}{ Labrale Inferius } & \multirow{2}{*}{ ClassI } & Female & 43 & 0.2170 & 0.02559 & \multirow{2}{*}{0.095} \\
\hline & & Male & 21 & 0.2295 & 0.02872 & \\
\hline
\end{tabular}




\begin{tabular}{|c|c|c|c|c|c|c|c|}
\hline \multirow{4}{*}{\multicolumn{2}{|c|}{ 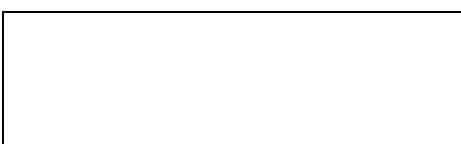 }} & \multirow[b]{2}{*}{ Classll } & Female & 54 & 0.2239 & 0.02536 & \multirow[b]{2}{*}{0.821} \\
\hline & & & Male & 10 & 0.2310 & 0.03107 & \\
\hline & & \multirow{2}{*}{ ClassIII } & Female & 42 & 0.2057 & 0.02586 & \multirow{2}{*}{0.020} \\
\hline & & & Male & 26 & 0.2231 & 0.02782 & \\
\hline
\end{tabular}

* given the division of soft tissue thickness values by the size of SN line, the mean data lack a measurement unit.

\begin{tabular}{|l|l|l|l|l|l|l|}
\cline { 2 - 7 } \multicolumn{1}{c|}{} & Class I VS II & Class I VS III & \multicolumn{2}{l|}{ Class II VS III } \\
\cline { 2 - 7 } \multicolumn{1}{c|}{} & Male & Female & Male & Female & Male & Female \\
\hline Glabella & 00502 & 00922 & 00197 & 00830 & 00083 & 00881 \\
\hline Nasion & 00416 & 00930 & 00917 & 00570 & 00309 & 00609 \\
\hline Rhinion & 00524 & 00338 & 00306 & 00987 & 1.000 & 00488 \\
\hline Subnasale & 00187 & 00016 & 00337 & 00006 & 00050 & P 0.001 \\
\hline Labrale Superius & 00050 & 00939 & 00045 & 00012 & 00001 & 00023 \\
\hline Stomion Superius & 00538 & 00399 & 00002 & 00076 & 0003 & 00029 \\
\hline Stomion Inferius & 00160 & 00484 & 00018 & 00063 & 00007 & 0.027 \\
\hline Labrale Inferius & 00538 & 00101 & 00676 & 00275 & 00752 & 0.017 \\
\hline Labiomentale & 00823 & 00865 & 00668 & 00191 & 00597 & 00194 \\
\hline Pogonion & 00190 & 00402 & 00741 & 00225 & 00123 & 00651 \\
\hline Gnathion & 00975 & 00580 & 00090 & 00308 & 00089 & 00798 \\
\hline
\end{tabular}

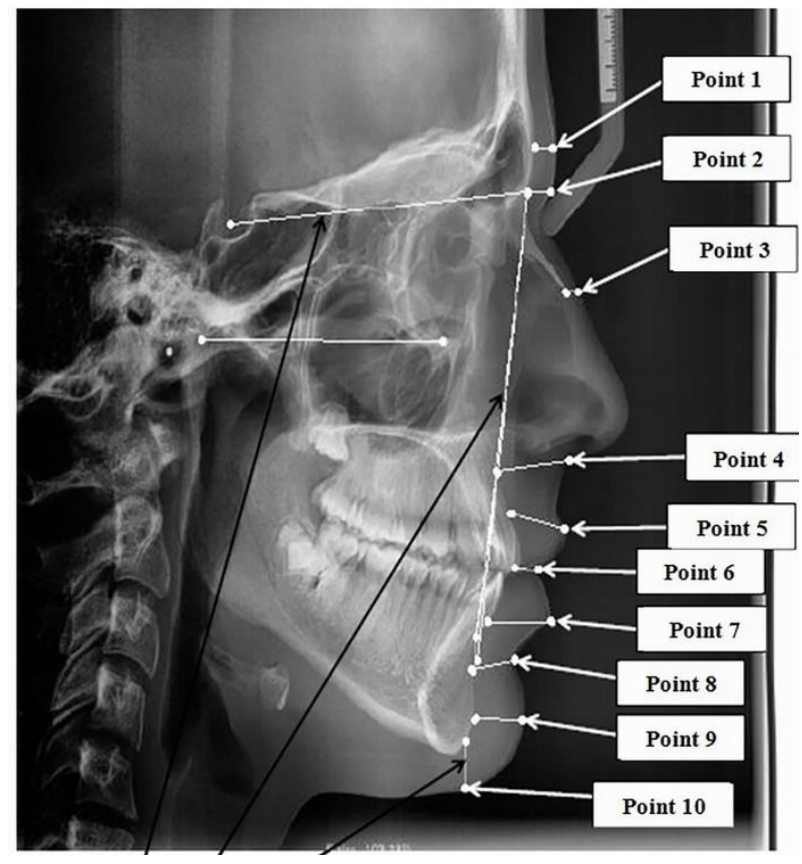

\section{DISCUSSION}

Facial reconstruction is aimed to identify unidentifiable corpses, and reconstruction of the soft tissue of the skull increases the possibility of facial identification. All the reconstruction techniques used in forensics are based on soft tissue thickness; therefore, such measurements are inevitable. ${ }^{24}$ To this end, it is necessary to know the mean thickness of soft tissue in specific areas of the face. This requires establishing a relationship between the measured dimensions and age, gender and race. ${ }^{26}$ Hence, in the present study, the mean values and standard deviations of soft tissue thickness in the aforementioned regions for different skeletal classes and both genders among an Iranian population were measured (Table 1).

As indicated in tables 1 and 2, the comparison of mean values among different skeletal classes showed significant differences only at sub nasale, labrale superius, stomion superius and stomion inferius points. Utsuno et al. reported differences in soft tissue thickness at labiomental, labrale superius, subnasal and pogonion points in a Japanese population. The difference between the results of that study and our findings may be due to racial differences. A review of articles in this regard reveals differences related to race and ethnicity. ${ }^{27}$

Skeletal classes I and II are more similar to each other in terms of soft tissue thickness compared to class III. Also, in people with class III skeletal pattern, soft tissue thickness at subnasal, labrale superius, stomion superius and stomion inferius points was higher than in other skeletal classes; this difference may be associated with genetic or environmental factors such as soft tissue compensation for covering or adapting to the skeletal status. Earlier in 2014, Pithon et al. ${ }^{18}$ performed a study of 300 Brazilian children aged 8-12 years, and in contrast to the current study, concluded that soft tissue thickness at the pogonion point was greater among those with class III skeletal complications. They reported the possible cause of this difference could be associated with genetics. The study of Utsuno et al. ${ }^{19}$ in 2014 among a Japanese population showed similar results to those of this study. They compared different skeletal classes and concluded that soft tissue thickness was higher in areas with lower skeletal growth.

Further, Kamak et al. ${ }^{20}$ observed reduced soft tissue thickness at regions with higher skeletal growth (e.g., labrale inferius in people with class III skeletal pattern), and proposed a theory on the effect of the position of middle incisors on soft tissue thickness. Moreover, WaqarJeelani et al. ${ }^{21}$ in a research on a Pakistani population found that the soft tissue thickness at glabella point in patients with class II skeletal pattern was higher. They attributed this issue to mandibular prognathism due to the high secretion of growth hormone. Also, they reported increased thickness of soft tissue at labrale superius, subnasal and stomion points in class III skeletal pattern, confirming the results of the present study. They considered the possible cause of this increase to be related to the camouflage activity of soft tissue in adaptation with skeletal discrepancy.

The results of Uysal et al. ${ }^{28}$ demonstrated a significant difference between male and female patients in soft tissue thickness at pogonion, labrale inferius, labrale superius, 
and menton points. Furthermore, this difference in thickness was higher in men than in women. One of the objectives of this study was to compare soft tissue thickness between the two sexes. The obtained findings showed that soft tissue thickness at labiomental, pogonion and gnathion points in class I skeletal pattern was lower in women than in men; this difference was significant at subnasal, labrale superius, stomion superius, stomion inferius, rhinion and nasion points. Hence, these differences in soft tissue thickness should be considered during facial reconstruction. Also, soft tissue thickness at areas diagnosed to be insignificant based on a special race can be used in facial reconstructions related to the same race. The study of WaqarJeelani et al. ${ }^{21}$ among a Pakistani population indicated similar results for labrale superius, subnasal, nasion and labrale inferius points.

As mentioned earlier, in these analyses age was proposed as an influential factor; thus, the samples in this study were aged $18-30$ years and were in CS6 stage in terms of vertebral maturation.

A factor affecting soft tissue thickness is the presence of vertical discrepancies in skeletal relations. For example, the study of Uysal et al. ${ }^{28}$ in 2009 on a Turkish population showed differences in soft tissue thickness between male and female cases at pogonion, labrale inferius, labrale superius and menton points. In other studies, soft tissue thickness in male patients was significantly more than in female patients. ${ }^{29,}{ }^{30}$ In 2012, Kamak et al. ${ }^{20}$ carried out a study on a population with the same race and concluded that soft tissue thickness at labiomental, glabellas, and pogonion points was higher in men. The discrepancy in results of these two studies may be associated with disregarding skeletal vertical relations in the second study. In the present study, normality of the vertical dimension was a criterion for inclusion in the study.

All the analyses in this study were performed digitally by Digimizer. V4.1.1.0 software. $^{25}$ The use of some features of this software such as magnification and changing the brightness and contrast of images provided the observer a better vision and more accuracy, minimizing the errors and facilitating the research procedures.

By dividing the measured values by the size of the SN line, the problems of magnification and body size of the samples were controlled. Based on the results of this study and similar ones on other populations, subnasal, labrale superius and stomion are the most diverse points among the studied populations ${ }^{18-21}$ and have the minimum capacity for reconstruction. Therefore, more accurate studies are suggested to be conducted on these points.

Arriving at a general conclusion based on a few studies is impossible. Moreover, the findings of various studies on populations with different racial backgrounds cannot be generalized. On the other hand, the impossibility of longitudinal studies in this regard because of ethical considerations in the preparation of radiographs from the study samples has always been a major limitation for the expansion of studies in this regard. Despite the difficulty in finding larger samples and the need for more time and accuracy to conduct studies on larger sample sizes, similar studies are recommended to be carried out on separate races (especially on Iranian race owing to the shortage of similar studies) with similar samples and growth-related aspects but without differences caused by surgeries to obtain more reliable results.

\section{CONCLUSIONS}

1. There was a significant difference between different skeletal classes at subnasal, labrale superius, stomion superius and stomion inferius points.

2. There were significant differences in soft tissue thickness between classes I and II at subnasal (class I>class II), between classes I and III at subnasal, labrale superius, stomion superius and stomion inferius points (class III>class I) and between classes II and III at subnasal, labrale superius, stomion superius and stomion inferius points (class III>class II).

3. There was a significant difference in soft tissue thickness in class I, which was lower in women than in men except for labiomental, pogonion and gnathion points. This difference was significant at subnasal, labrale superius, stomion superius, stomion inferius, rhinion and nasion points.

4. There was a significant difference in women between skeletal classes I and II at subnasal point (class I>class II), between classes I and III at subnasal and labrale superius points (class III>class I) and between classes II and III at subnasal, labrale superius, stomion superius, stomion inferius (class III>class II) and labrale inferius points (class II>class III).

5. There was a significant difference in men between skeletal classes I and III at labrale superius, stomion superius and stomion inferius points (class III>class I) and between classes II and III at labrale superius, stomion superius and stomion inferius points (class III>class II).

6. There was a small positive correlation between the numerical values of soft tissue thickness and skeletal class.

7. There was a small negative correlation between the numerical values of soft tissue thickness and numerical values of the skeletal class determinant (ANB) at subnasal, labrale superius and stomion superius points and a negligible positive correlation between the aforementioned indices at labrale inferius and labiomental points.

Acknowledgment: The authors thank Vice Chancellery for research, Isfahan University of Medical Sciences, for financial support (\#395844).

\section{REFERENCES}

1. Arnett GW, Bergman RT. Facial keys to orthodontic diagnosis and treatment planning. Part I. American journal of orthodontics and dentofacial orthopedics. 1993;103(4):299312.

2. Manhein MH, Listi GA, Barsley RE, Musselman R, Barrow $\mathrm{NE}$, Ubelaker $\mathrm{DH}$. In vivo facial tissue depth measurements for children and adults. Journal of Forensic Science. 2000;45(1):48-60.

3. De Greef S, Willems G. Three-dimensional cranio-facial reconstruction in forensic identification: latest progress and new tendencies in the 21st century. Journal of Forensic Science. 2005;50(1):JFS2004117-6. 
4. Black S, Ferguson E. Forensic anthropology: 2000 to 2010: CRC Press; 2011.

5. Sahni D, Singh G, Jit I, Singh P. Facial soft tissue thickness in northwest Indian adults. Forensic science international. 2008;176(2-3):137-46.

6. Suzuki H. On the thickness of the soft parts of the Japanese face. J Anthropol Soc Nippon. 1948;60:7-11.

7. De Greef S, Claes P, Vandermeulen D, Mollemans W, Suetens P, Willems G. Large-scale in-vivo Caucasian facial soft tissue thickness database for craniofacial reconstruction. Forensic science international. 2006;159:S126-S46.

8. Noor NFM, Basri R, Alam MK, Haque S, Hao MSJ, Talib MA. Soft Tissue Cephalometric Measurements Among Malaysian Malays and Chinese. Pesquisa Brasileira em Odontopediatria e Clínica Integrada. 2020;20.

9. Kim K-D, Ruprecht A, Wang G, Lee JB, Dawson DV, Vannier MW. Accuracy of facial soft tissue thickness measurements in personal computer-based multiplanar reconstructed computed tomographic images. Forensic science international. 2005;155(1):28-34.

10. Wilkinson C. Computerized forensic facial reconstruction. Forensic Science, Medicine, and Pathology. 2005;1(3):1737.

11. Claes $P$, Vandermeulen D, De Greef S, Willems G, Clement JG, Suetens P. Computerized craniofacial reconstruction: conceptual framework and review. Forensic science international. 2010;201(1-3):138-45.

12. Tedeschi-Oliveira SV, Melani RFH, de Almeida NH, de Paiva LAS. Facial soft tissue thickness of Brazilian adults. Forensic science international. 2009;193(1-3):127. e1-. e7.

13. Kurkcuoglu A, Pelin C, Ozener B, Zagyapan R, Sahinoglu Z, Yazıcı AC. Facial soft tissue thickness in individuals with different occlusion patterns in adult Turkish subjects. Homo. 2011;62(4):288-97.

14. Claes P, Vandermeulen D, De Greef S, Willems G, Suetens $P$. Craniofacial reconstruction using a combined statistical model of face shape and soft tissue depths: methodology and validation. Forensic science international 2006;159:S147-S58.

15. Sarilita E, Rynn C, Mossey PA, Black S, Oscandar F. Facial average soft tissue depth variation based on skeletal classes in Indonesian adult population: A retrospective lateral cephalometric study. Legal Medicine. 2020;43:101665.

16. Miyasaka S, Yoshino M, Imaizumi K, Seta S. The computeraided facial reconstruction system. Forensic science international. 1995;74(1-2):155-65.

17. Proffit WR, Fields HW, Larson B, Sarver DM. Contemporary orthodontics-e-book: Elsevier Health Sciences; 2018.
18. Pithon MM, Ribeiro DLR, dos Santos RL, de Santana CL, Cruz JPP. Soft tissue thickness in young north eastern Brazilian individuals with different skeletal classes. Journal of forensic and legal medicine. 2014;22:115-20.

19. Utsuno H, Kageyama T, Uchida K, Kibayashi K. Facial soft tissue thickness differences among three skeletal classes in Japanese population. Forensic science international. 2014;236:175-80.

20. Kamak H, Celikoglu M. Facial soft tissue thickness among skeletal malocclusions: is there a difference? Korean journal of orthodontics. 2012;42(1):23.

21. Jeelani W, Fida M, Shaikh A. Facial soft tissue thickness among three skeletal classes in adult Pakistani subjects. Journal of forensic sciences. 2015;60(6):1420-5.

22. Gungor K, Bulut O, Hizliol I, Hekimoglu B, Gurcan S. Variations of midline facial soft tissue thicknesses among three skeletal classes in Central Anatolian adults. Legal Medicine. 2015;17(6):459-66.

23. Jacobson A, White L. Radiographic cephalometry: from basics to 3-D imaging. American Journal of Orthodontics and Dentofacial Orthopedics. 2007;131(4):S133.

24. Utsuno H, Kageyama T, Deguchi T, Umemura Y, Yoshino M, Nakamura $\mathrm{H}$, et al. Facial soft tissue thickness in skeletal type I Japanese children. Forensic science international. 2007;172(2-3):137-43.

25. Farazdaghi H, Tavakoli MB, Etemadi S, Ghodousi A. Assessment of sphenoid sinus volume in order to determine sexual identity, using multi-slice CT images. Journal of Dental Medicine. 2017;29(3):187-93.

26. Fourie Z, Damstra J, Gerrits PO, Ren Y. Accuracy and reliability of facial soft tissue depth measurements using cone beam computer tomography. Forensic science international. 2010;199(1-3):9-14.

27. Utsuno H, Kageyama T, Uchida K, Yoshino M, Oohigashi S, Miyazawa $\mathrm{H}$, et al. Pilot study of facial soft tissue thickness differences among three skeletal classes in Japanese females. Forensic science international. 2010;195(1-3):165. e1-. e5.

28. Uysal T, Yagci A, Basciftci FA, Sisman Y. Standards of soft tissue Arnett analysis for surgical planning in Turkish adults. The European Journal of Orthodontics. 2009;31(4):449-56.

29. Basciftci FA, Uysal T, Buyukerkmen A. Determination of Holdaway soft tissue norms in Anatolian Turkish adults. American journal of orthodontics and dentofacial orthopedics. 2003;123(4):395-400.

30. Hamdan AM. Soft tissue morphology of Jordanian adolescents. The Angle Orthodontist. 2010;80(1):80-5. 